NBER WORKING PAPER SERIES

THE IMPLICATIONS OF AN ENDOGENOUS MONEY SUPPLY FOR MONETARY NEUTRALITY

Robert G. King

Bharat Trehan

Working Paper No. 1175

NATIONAL BUREAU OF ECONOMIC RESEARCH

1050 Massachusetts Avenue

Cambridge MA 02138

August 1983

The research reported here is part of the NBER's research program in Economic Fluctuations. Any opinions expressed are those of the authors and not those of the National Bureau of Economic Research. 


\section{The Implications of an Endogenous Money Supply \\ for Monetary Neutrality}

\section{ABSTRACT}

This paper examines the implications of an endogenous money supply for the perceived (by econometricians) and actual nonneutrality of money in rational expectations models of the class put forward by Lucas (1972, 1973) and Barro (1976, 1980) that stress incomplete information. First, if there is contemporaneous policy response (e.g., to interest rates), then a simultaneous equations bias produces inconsistency in tests that use contemporaneous monetary statistics such as those proposed by King (1981) and Boschen-Grossman (1983). Thus, an econometrician might erroneously conclude that money is nonneutral in a fully classical model. Second, if money acts as a 'signal' about economic conditions then autonomous (policy induced) changes in the money stock can have real effects. In contrast to the nonneutrality of money in the LucasBarro analysis, which arises due to incomplete information about monetary aggregates, this nonneutrality requires that monetary information be utilized by economic agents.

Robert G. King
Bharat Trehan
Department of Economics
University of Rochester
Rochester, NY 14627
(716) $275-3895$ 


\section{The Implications of an Endogenous Money Supply for Monetary Neutrality ${ }^{1}$}

The nonneutrality of exogenous monetary changes in the rational expectations/monetarist models of Lucas $(1972,1973)$ and Barro $(1976,1980)$ arises as a consequence of imperfect information. In these setups, economic agents do not directly observe the quantity of money and, consequently, mistakenly perceive changes in nominal prices as reflecting altered relative opportunities. However, as King (1981) points out, if a monetary statistic is contemporaneously observable (even with some noise) then the Lucas-Barro models predict a zero correlation between output and monetary statistics, as perceived variations in money are neutral in these models. Using quarterly post-war U.S. data, Boschen and Grossman (1982) find a significant non-zero correlation between output and contemporaneous monetary statistics, which leads to a rejection of the Lucas-Barro model if agents are (plausibly) assumed to posess such statistics.

If money is endogenous and observable, however, then important modifications of both theory and econometric procedures are necessary, as we demonstrate in this paper. First, even if money is fully neutral, endogeneity implies that the zero-correlation hypothesis tested by Boschen-Grossman is not an implication of the rational expectations/monetarist models of Lucas and Barro. We describe an econometric procedure that can handle some forms of this 'simultaneous equations' bias, producing a valid test of the neutrality hypothesis. Second, if money serves as a 'signal' about economic conditions--say, because agents do not observe some other aggregate state variable with

1 Helpful discussions with John F. Boschen, Michael Dotsey, and Charles I. Plosser are acknowledged. Herschel Grossman has contributed substantially to clarifying the empirical implications of the model developed in Section III. 
which money is correlated--then autonomous movements in money can have real effects. This nonneutrality requires that money be observed by economic agents, a polar opposite assumption to that made by Lucas and Barro. However, for this nonneutrality to arise, it is still central that information is imperfect, in the sense that agents are unable to observe all the shocks that impact upon the system.

The organization of the remainder of the paper is as follows. In section I, we review the basic relationship between money and economic activity in equilibrium models, using Barro's (1980) model as our organizing framework. In section II, we look at neutrality tests under some alternative assumptions about monetary information and the money supply process, working within a model in which the contemporaneously perceived component of money is actually neutral. We discuss some spurious rejections of the neutrality hypothesis that may emerge when money is endogenous and suggest an econometric procedure that deals with one class of these problems. In section III, our focus shifts to an equilibrium model with a substantially different economic mechanism, in which autonomous movements in a partly endogenous money aggregate are nonneutral because they are a valuable, but imperfect, 'signal' about economic conditions. Section IV is a brief summary and conclusions.

\section{Equilibrium Models, Expectations, and Money}

The analysis in parts II and III below employs a variant of the business cycle model constructed by Barro (1980). Here, we give a brief review of this model and describe the special features that are important for our paper.

In common with the general class of models put forward by Lucas (1977), there is a single final product that is traded in a large number of decentralized exchange locations $(z=1,2, \ldots, z)$. In each location, the commodity supply and demand schedules are given by the following log-linear specifications: 
(1) $y_{t}^{s}(z)=k_{t}^{s}(z)+\alpha^{s} r_{t}(z)-\beta^{s} a_{t}(z)+\theta_{1}^{s} n_{t}+\varepsilon_{t}^{s}(z)$

$$
\begin{gathered}
y_{t}^{d}(z)=k_{t}^{d}(z)-\alpha r_{t}^{d}(z)+\beta^{s} a_{t}(z)+\theta_{1}^{d} \eta_{t} \\
+\theta_{2} E_{z} \eta_{t+1}+\varepsilon_{t}^{d}(z),
\end{gathered}
$$

where the parameters $\alpha, \beta$, and $\theta$ are all taken to be positive. As in Barro's models $(1976,1980)$, commodity supply depends on a systematic component $\left(k_{t}^{S}(z)\right)$, the relevant rate of return from the perspective of market $z$ $\left(r_{t}(z)\right)$, a local supply disturbance $\left(\varepsilon_{t}^{s}(z)\right)$, and on a wealth term, $a_{t}(z)$. Commodity demand is specified with symmetric, though opposite influences.

The model also incorporates a permanent aggregate disturbance $n_{t}$, which affects both supply and demand in the current period. In addition, commodity demand is assumed to depend positively on the locally perceived future value of this disturbance $\left(E_{z} n_{t+1}\right) .^{2}$ One rationalization of such a specification would be that $n_{t}$ represents shifts in the marginal efficiency of capital. The resulting investment responses would generally be larger if they are foreseen $\left(\theta_{2}>\theta_{1} \equiv \theta_{1}^{d}+\theta_{1}^{s}>0\right)$. However, a complete analysis of capital accumulation would involve many issues that are tangential to the main issues of this paper. ${ }^{3}$

Local commodity market equilibrium determines a real rate of return and quantity of output as functions of the various shift variables discussed above.

2 Throughout our discussion, we use the shorthand notation $E_{z} x_{t}$ to denote the rational expectation of the variable $x_{t}$ based on the information set $I_{t}(z)$ possessed by agents in market $z$.

3 Lucas (1975), King (1981), and Trehan (1982) discuss aspects of incorporating capital accumulation into this sort of model. 


$$
\begin{aligned}
r_{t}(z)=\frac{1}{\alpha} k_{t}^{d}(z)-\frac{1}{\alpha} k_{t}^{s}(z)+\frac{\beta}{\alpha} a_{t}(z) & \\
& +\frac{\theta_{1}^{s}-\theta \frac{1}{\alpha}}{\alpha} \eta_{t}+\frac{\theta_{2}}{\alpha} E_{z} \eta_{t+1}+\frac{1}{\alpha} \varepsilon_{t}^{d}(z)-\frac{1}{\alpha} \varepsilon_{t}^{s}(z)
\end{aligned}
$$

$$
\begin{aligned}
y_{t}(z)=\frac{\alpha^{s}}{\alpha} k_{t}^{d}(z)+\frac{\alpha}{\alpha} k_{t}^{s}(z)+\frac{H}{\alpha} a_{t}(z) \\
+\frac{G}{\alpha} \eta_{t}+\frac{\alpha \theta_{2}}{\alpha} E_{z} \eta_{t+1}+\frac{\alpha}{\alpha} \varepsilon_{t}^{d}(z)+\frac{\alpha}{\alpha} \varepsilon_{t}^{s}(z)
\end{aligned}
$$

where $\alpha=\alpha^{s}+\alpha^{d}, \beta=\beta^{s}+\beta^{d}, H=\alpha^{s} \beta^{d}-\beta^{s} \alpha$, and $G=\alpha^{s} \theta_{1}^{d}+\alpha^{d} \theta_{1}^{s}$.

The market clearing value of output $y_{t}(z)$ depends positively on locally perceived wealth if $H=\alpha^{3} \beta^{d}-\beta^{s} \alpha^{d}>0$, which will be assumed below, ${ }^{4}$ and positively on the perceived value of the future disturbance $E_{z} \eta_{t+1}$. The discussion below will center on $a_{t}(z)$ and $E_{z} \eta_{t+1}$ as channels of influence for monetary variables on real activity.

Since there is a nominal inside bond in Barro's model, the relevant real rate of return from the perspective of market $z$ is $R_{t}+P_{t}(z)-E_{z} P_{t+1}$, where $P_{t}(z)$ is the logarithm of the price in market $z$ at date $t$ and $P_{t+1}$ is the logarithm of the general price level at date $t+1$.

The aggregate portfolio balance condition (5) specifies that the logarithm of the nominal money stock equals the logarithm of nominal money demand. Nominal money demand depends positively on the general price level and the level of economy-wide average real balances $T_{t}$, which depends on economy-wide average real income $\left(y_{t}\right)$ and the nominal interest rate $\left(R_{t}\right)$ in conventional ways.

$$
M_{t}^{s}=M_{t}^{d}=P_{t}+T_{t}=P_{t}+\delta y_{t}-\gamma R_{t}+\mu_{t}
$$

4 Barro and King (1982) point out that time separable preferences imply that $\mathrm{H}=0$, so that this channel may not be relevant. Yet, for our general purposes this mechanism for monetary effects on real output is as good as any other. 
where $M_{t}^{S}$ is the nominal money supply, $M_{t}^{d}$ is nominal money demand and $\mu_{t}$ is a shift term. This condition and economy-wide averages of (3) and (4) determine the price level and the nominal interest rate.

Following Archibald and Lipsey (1958) and Barro (1980), it is assumed that money is wealth only to the extent that there is a gap between real balances held and those desired for transactions purposes, which neglects the income effects of the flow of transactions services derived from money holding. Specifically, we assume that $a_{t}(z)=\left\{M_{t}+E_{z} \Delta M_{t+1}-E_{z} P_{t+1}\right\}-E_{z} T_{t+1}$. Imposing the expected future version of the monetary equilibrium condition (5) on the model, it then follows that $a_{t}(z)=M_{t}-E_{z} M_{t}$ (for a detailed discussion and alternative derivation, see Barro (1980)).

Consequently, economy-wide average output depends on the money stock only to the extent that variations in this quantity are not generally recognized to be taking place. Now, assuming that $\eta_{t}=\eta_{t-1}+v_{t}$, where $v_{t}$ is serially independent and distributed $\mathrm{N}\left(0, \sigma_{\mathrm{v}}^{2}\right)$, we obtain economy-wide average output as :

(6) $\quad y_{t}=\bar{y}_{t}+\frac{H}{\alpha}\left(M_{t}-\overline{E_{z} M_{t}}\right)+\frac{\alpha}{\alpha} \theta_{2} \overline{E_{z} v_{t}}+\frac{G}{\alpha} v_{t}$ with $\tilde{y}_{t}=\frac{\alpha^{s}}{\alpha} k_{t}^{d}+\frac{\alpha}{\alpha} k_{t}^{s}+\frac{G+\alpha^{s} \theta_{2}}{\alpha} \eta_{t-1}$, where $k_{t}^{d}$ is the economy-wide average value of $k_{t}^{d}(z)$, etc. $\overline{\left(E_{z} x_{t}\right.}$ denotes an economy-wide average expectation, here and below).

The expression for aggregate output (6) derived from our particular model : shares key features with other members of the class of equilibrium business cycle models put forward by Lucas, Barro and others. In particular, perceived monetary disturbances--changes affecting $M_{t}$ and $E_{z} M_{t}$ equally--are irrelevant for output determination. Our model also incorporates a role for the actual 
and perceived value of the aggregate disturbances, $v_{t}$, for which we have suggested a technological interpretation. It should be pointed out that for the bulk of our analysis, it is (6) that is key, rather than the particular structural model from which it is derived.

The Money Supply Process and Monetary Information

To close the model, it is necessary to specify how the quantity of money evolves over time. We assume that the money stock is the outcome of two components, the money multiplier and the monetary base, so that the growth rate of money may be divided into multiplier growth $\left(\phi_{t}\right)$ and base growth $\left(h_{t}\right)$.

$$
M_{t}-M_{t-1}=\phi_{t}+h_{t}
$$

We make the following assumptions about the evolution of these components. Each has a portion that is predictable on the basis of previous information, which we denote $E_{t-1} \phi_{t}$ and $E h_{t-1}$. The unpredictable component of money growth we denote $m_{t}=\phi_{t}-\underset{t-1}{E} \phi_{t}+\left(h_{t}-\underset{t-1}{E} h_{t}\right)$. In the discussion below, we consider the following alternative assumptions about the exogeneity and observability of $m_{t}$ :

(8a) $m_{t}$ is not observable and is an independent, normal variable

(8b) $m_{t}$ is observable and is an independent, normal variable

(8c) $\mathrm{m}_{t}$ is the sum of two independent normal variables. The first, $g_{t}=\left(h_{t}-E h_{t-1}\right)$, is observable and the second, $x_{t}=\left(\phi_{t}-\underset{t-1}{E} \phi_{t}\right)$, is not.

(8d) $\quad m_{t}=\psi_{1} v_{t}+w_{t}$ and is observable

(8e) $\quad m_{t}=\psi_{2}\left(R_{t}-\underset{t-1}{E} R_{t}\right)+w_{t}$ and is observable 
where, in both ( $8 \mathrm{~d})$ and $(8 \mathrm{e}), \mathrm{w}_{\mathrm{t}}$ is an independent, normal variable.

In the former three specifications, the money supply is an exogenous variable with respect to output, although three contrasting assumptions about its observability by economic agents are made. First, (8a) represents the Lucas-Barro hypothesis that agents do not posess contemporaneous monetary statistics. Alternatively, as in King (1981) and Boschen-Grossman (1982), $(8 b)$ assumes that agents have contemporaneous monetary information.. Specification (8c) represents an intermediate case where agents are assumed to observe high powered money but not the monetary multiplier within the decision period.

In the latter two specifications, we allow the money supply to be endogenous and assume that it is observable by economic agents. In ( $8 \mathrm{~d}$ ) the money supply reacts to the aggregate shock, $v_{t}$. Below, we discuss two alternative interpretations for $v_{t}$ and the reasons such a response may be observed. Finally in (8e), this dependence is assumed to derive from a response to nominal interest rate movements, a pattern of behavior that is frequently asserted to describe central bank operating policies (see, for example, Poole (1975)). In our setup, this dependence might plausibily derive from either reserve management activities of banks that affect the growth of the multiplier $\left(\phi_{t}\right)$ or central bank operating policies that lead to a dependence of the growth in the monetary base $\left(h_{t}\right)$ on the interest rate.

\section{Neutrality Tests}

The basis for neutrality tests is the observation that perceived monetary growth does not affect output in Lucas-type business cycle models. However, the elements of money that are unperceived depend in an essential way on the information structure of the model. In this section we discuss some neutral- 
ity tests employing a output specification that is a special case of (6), in that perceptions of real variables are irrelevant to output determination $\left(\theta_{2}=0\right)$.

\section{Anticipated Money Growth}

Barro and others have tested the neutrality of anticipated money growth, which is one implication of the sort of model we discuss here. If we maintain that money is not contemporaneously observable, it is necessary to decompose money into its anticipated and unanticipated components, because unanticipated money can have real effects if it is also unperceived. Testing is complicated because the construct unperceived money $\left(M_{t}-E_{z} M_{t}=m_{t}-E_{z} m_{t}\right)$ depends in complicated ways on the elements of information sets. However, if money is not directly observable but agents do observe local prices and interest rates, then it can be shown that unanticipated monetary events typically exert a positive but less than one-to-one impact on unperceived money $\left(m_{t}-E_{z} m_{t}\right)$ because agents learn about monetary shocks from the available price signals (see Barro (1980) and King (1983) for some detailed discussions). Thus, under our informational assumption ( 8 a), there will be a causal, positive influence of unanticipated money growth on output, which Lucas and Barro have stressed. Anticipated money growth, which is perceived, will not have this property.

\section{Contemporaneous Monetary Information}

When contemporaneous monetary information is available, however, matters are altered substantially. If money is accurately observable, as under our assumption (8b), then the gap $m_{t}-E_{z} m_{t}$ will necessarily be zero if economic agents use information efficiently. King (1981) discussed how this result extends to models in which money is not accurately observed but, instead, is 
corrupted by a temporary measurement error. Essentially, since unperceived money takes the form of an 'expectation error,' it should not be correlated with any information variable that economic agents use to form expectations. Thus, output should be uncorrelated with contemporaneously observed monetary statistics, even if these are imperfect indicators of the stock of money. That is, given that output depends on real variables and unperceived money, in the restricted form of (6) that we are using, $y_{t}=\ddot{y}_{t}+\frac{H}{\alpha}\left(m_{t}-\overline{E_{z} m_{t}}\right)+\frac{G}{\alpha} v_{t}$, then it follows that a test of the neutrality proposition may be obtained by a regression of output on contemporaneous monetary statistics. The twin hypotheses of (i) neutrality of perceived money growth and (ii) rational expectations based on contemporaneous information imply a zero regression coefficient in this case.

Boschen (1981) and Boschen-Grossman (1982) employ such tests on quarterly post-war data for the United States. ${ }^{5}$ Using a variety of specifications, measures of money, and real activity, they document that estimated regression coefficients typically differ from zero at conventional statistical levels.

One potential explanation of these results is that the relevant monetary aggregate is only partly observed, which could correspond to our case (8c). In this case, variations in the monetary base would be neutral--because they were rapidly perceived--while variations in the money multiplier would be 5 In this quick summary of the Boschen-Grossman work, we gloss over the important contribution that their theoretical analysis makes to formulating the neutrality test in an empirically tractable manner. The difficulty is that actual money growth, $M_{t}-M_{t-1}$, involves both an anticipated and unanticipated component. In principle, spurious rejection of the neutrality hypothesis could emerge if there were a correlation between $y_{t}$ (anticipated output) and $E M_{t}-M_{t-1}$ (anticipated money) through the operation of a feedback policy rule by the monetary authority. Two solutions to this potential problem appear available. The first is to 'hold fixed' separately the elements of $\tilde{y}_{t}$ in the regression. The second is to purge money of its anticipated component. Boschen-Grossman opt for the former procedure, which they implement empirically by viewing $y_{t}$ as a distributed lag of past $y_{t}$. 
nonneutral. Hence, the correct formulation of the neutrality test using contemporaneous monetary information would use the base rather than a broader monetary aggregate. John Boschen has suggested to us that such tests would not result in rejection of the neutrality hypothesis, at least for the second half of the post-war period, based on some preliminary empirical results that obtained in his thesis research (1981). This distinction is clearly worth exploring in future empirical research.

\section{Endogenous Unexpected Money}

If the unpredictable movements in money, $m_{t}$, are endogenous--in the sense of being correlated with autonomous determinants of output, $v_{t}$, in the structural model above--then spurious rejections of the neutrality hypothesis may occur even if it is actually true. To discuss this point and econometric procedures that may be appropriate, we consider in turn the policy specification $(8 \mathrm{~d}, \mathrm{e})$, each of which involves the assumption that agents accurately observe the money stock. Consequently, unperceived money will be zero in each case. For (8d) we take an alternative interpretation of $v_{t}$, and let it represent government spending. This specification then implies that part of government spending is financed by printing new money. It is assumed that government spending is determined exogenously and that all spending is temporary, so that $\eta_{t}=v_{t}$ here. Notjce that the issue of whether the spending is permanent or temporary serves only to determine the size of the $\theta$ coefficients in the supply and demand equations above.

Under these assumptions, (6) becomes $y_{t}=\tilde{y}_{t}+\frac{G}{\alpha} v_{t}$. A regression of output on money will produce a positive coefficient even when both money and government spending are perfectly observable due to the 'common effect' of $v_{t}$.

6 Boschen ( 1981 , pp. 26-28) discusses the changing reporting procedures used by the Federal Reserve System over the post-war period. 
Specification ( 8 e) differs from the preceeding case in that money is assumed to react to unpredictable changes in the nominal interest rate, which is endogenous in the model considered above. In the present case, $v_{t}$ can be interpreted either as a technological shock or a shock to government spending. Then a simple regression of output on the contemporaneous monetary statistic and $\tilde{y}_{t}$ will generally yield a non-zero regression coefficient, i.e., (9) $y_{t}=\tilde{y}_{t}+c\left(m_{t}\right)$, where $c=\psi_{2} \frac{G}{\alpha} \operatorname{cov}\left(R_{t}-\underset{t-1}{E} R_{t}, v_{t}\right) / \operatorname{var}\left(m_{t}\right)$.

Thus, changes in money supply and output will be positively correlated (recall that the money supply reacts positively to interest rate changes) as long as the technological disturbance leads to a higher interest rate. From (3) above, this will be the case as long as $\theta_{1}^{d}>\theta_{1}^{s}$. Even if this is not the case, the example above clearly brings out the potential for spurious rejections of the neutrality hypothesis.

If the parameters of the policy reaction function are known, then it is easy to correct for the correlations discussed in the two examples above. In these cases all that is required is to make an adjustment for that part of the change in money supply which is endogenous. A regression of $y_{t}$ on $\left(m_{t}-\psi_{2}\left(R_{t}-\underset{t-1}{E} R_{t}\right)\right)$ would then be the correct method of testing for neutrality. More generally, the parameter $\psi_{2}$ could be estimated if we had one or more exogenous variables that affected the nominal interest rate. A second : stage test of the neutrality hypothesis could use the estimated valus of $\psi_{2}$.

It bears emphasizing that in both the examples above money is fully neutral, i.e., variations in money supply have no effect on output. The positive correlation between observed money and output occurs solely as a result of 
permitting money to be endogenous. Further, endogeneity may provide an alternative explanation for Boschen's finding that the neutrality hypothesis cannot be rejected if the monetary base is used as the relevant aggregate. To the extent that the multiplier is 'more' endogenous than the base, the discussion indicates that it would be more highly correlated with output than the latter. $^{7}$

\section{Money as a Signal}

In this section, we introduce the possibility that autonomous monetary disturbances are nonneutral because agents view monetary statistics as conveying valuable information about economic conditions. In principle, the signalling role could arise either because the monetary authorities had access to superior information or, more plausibly, because the money supply responds endogenous $1 y$ to aggregate state variables that are not directly observable.

For the present purposes, it is key that the money stock is observable (though it need not be observed without noise) and endogenous, so that we employ specification (8d) above. Further, we maintain the imperfect information assumption in the sense that agents cannot observe the aggregate disturbances $w_{t}$ and $v_{t}$ that hit the system. For concreteness, we interpret $v_{t}$ as the current shock to technology, so that the current state of technology is given by $\eta_{t}=n_{t-1}+v_{t}$. Under the policy rule $(8 d)$, money reacts directly to the technology shock $v_{t}$, i.e., $m_{t}=\psi_{1} v_{t}+w_{t}$, and also involves an autonomous component $w_{t}$. Such a positive endogenous response $\left(\psi_{1}>0\right)$ may occur, for example, if a sudden realization of profitable investment opportunities

7 The bulk of the business cycle correlation between output and monetary magnitudes is with banking system measures. For example, Friedman and Schwartz (1963, Chapter 7) stress that changes in the money multiplier represent the major source of monetary change throughout the Great Contraction. Working from a different perspective, King and Plosser (1981) show that high powered money is weakly correlated with output fluctuations while deposits are significantly positively correlated over the post war period. 
induces firms to borrow from banks.

As previously, output determination is influenced by unperceived money $\left(m_{t}-E_{z} m_{t}\right)$, the technology shock $v_{t}$ and the economy-wide average perceived value of the technology shock $\left(\overline{\mathrm{E}_{z} \mathrm{v}_{t}}\right)$, as shown in (6) above. However, under our assumption that money is accurately observable, it is direct that $m_{t}=E_{z} m_{t}$, so that aggregate output takes the form

(10) $y_{t}=\tilde{y}_{t}+\frac{\alpha^{S} \theta_{2}}{\alpha} \overline{E_{z} v_{t}}+\frac{G}{\alpha} v_{t}$.

This expression emphasizes that the expectational channel by which money can be nonneutral is $\overline{E_{z} v_{t}}$, the perceived value of the technology shock.

The nature of the rational expectations solution for $\overline{E_{z} v_{t}}$ as a function of information variables depends on the information set, which in principle would involve the current money supply, the nominal interest rate and the local price. However, a full-blown solution for $\overline{E_{z} v_{t}}$ becomes extremely complicated in this model if several signals are used (see, for example, Barro (1980) in which there are two signals). Therefore, for illustrative purposes, we first discuss expectation formation under the assumption that the only signal that agents possess is the current money stock.

Given the linear normal structure of the model, it follows that agents' one signal rule will take the following simple form.

$$
E_{z} v_{t}=\gamma\left(\psi_{1} v_{t}+w_{t}\right)
$$

where $\gamma=\psi_{1} \sigma_{v}^{2} /\left(\psi_{1}^{2} \sigma_{v}^{2}+\sigma_{\mathrm{w}}^{2}\right)$ is the population coefficient for a regression of $v_{t}$ on $m_{t}$. Further, given that the monetary signal is assumed to be the only source of information, expectations do not differ across markets. Thus, it follows that average expectations $\overline{E_{z} v_{t}}$ respond by less than one-to- 
one with $v_{t}$ (since $0<\psi_{1} \gamma<1$ ) and positively to autonomous monetary shocks $w_{t}$ if there is a positive relationship between money and technology shocks $\left(\psi_{1}>0\right)$. In this case, random increases in the money supply raise output, according to (10) above, because agents treat these fluctuations as signalling positive movements in $v_{t}$, e.g., indicating an increase in the future profitability of investment.

The fact that the output effect of autonomous movements in money $\left(w_{t}\right)$ is positive (given $\psi_{1}>0$ ) is easily seen. Substituting (11) in (10) gives a reduced form expression that links output to the fundamental shocks $v_{t}$ and $w_{t}$.

$$
y_{t}-\tilde{y}_{t}=\frac{\alpha^{s} \theta_{2}}{\alpha} \gamma\left[\psi_{1} v_{t}+w_{t}\right]+\frac{G}{\alpha} v_{t} \text {. }
$$

Further, using policy specification ( $8 d$ ), we obtain

$$
\operatorname{Cov}\left[\left(y_{t}-\tilde{y}_{t}\right)\left(M_{t}-M_{t-1}\right)\right]=\frac{1}{\alpha}\left\{\alpha^{s} \theta_{2}+G\right\} \psi_{1} \sigma_{v}^{2}
$$

which is unambiguously positive for $\psi_{1}>0$. Therefore, the coefficient obtained from regressing output on money will be positive.

Thus, in the present model, (12) demonstrates that there is a true causal relationship that exists between autonomous monetary movements ( $w_{t}$ ) and output, with a positive influence existing so long as agent's perceptions of the unobservable real aggregate shock $\left(v_{t}\right)$ are positively related to the observed aggregate (i.e., $\gamma=\psi_{1} \sigma_{\mathrm{v}}^{2} /\left(\psi_{1}^{2} \sigma_{\mathrm{v}}^{2}+\sigma_{\mathrm{w}}^{2}\right)>0$ ). Further, there is a positive covariance between output and measured money under the same conditions $\left(\psi_{1}>0\right)$, in view of $(13)$.

However, the covariance calculated in (13) is not informative about the empirical relevance of the key element of this model, which is the nonneutrality mechanism. ${ }^{8}$ Specifically, suppose that one adopts the alternative hypothe-

8 We thank Herschel Grossman for pointing out this equivalence to us and stressing its implications. 
sis--advanced, for example, by King and Plosser (1981)--that attributes the comovements of money and output to the fact that these variables both respond to aggregate real shocks that are observable by economic agents. In the current setup, this implies that output is simply given by

(10)' $y_{t}-\tilde{y}_{t}=\frac{\alpha^{s} \theta_{2}+G}{\alpha} v_{t}$,

which follows from (10) above by replacing $E_{z} v_{t}$ with $v_{t}$. This model also generates the covariance (13), which in fact will be produced by any model in which money is a common component of the information set on which $E_{z} v_{t}$ is based. ${ }^{9}$

That this covariance is silent on the predictions of our model implies that empirical strategies must isolate contemporaneously unperceived components of autonomous money growth (our $w_{t}$ ) to test the key predictions of our model, i.e., the expectational nonneutrality displayed in (10) versus alternative theories (such as $\left.(10)^{\prime}\right)$. We are presently investigating the feasibility of some alternative empirical strategies. One attractive possibility ${ }^{20}$ is to examine the implications of money supply 'announcements'--studied previously by Cornell (1983), Engel and Frankel (1982) and others--in the context of our theory, particularly investigating implications for interest rates, commodity prices and production.

9 To see this, note that (10) may be viritten as $y_{t}-\tilde{y}_{t}=\frac{\alpha^{s} \theta+G}{\alpha} w_{t}-\frac{\alpha^{s} \theta}{\alpha}\left(v_{t}-\overline{E_{z} v_{t}}\right)$.

A basic property of rational expectations is that the expectation error $\left(v_{t}-E_{z} v_{t}\right)$ will always be uncorrelated with elements of $I_{t}(z)$, such as money growth in our setup.

10 Suggested to us by Michael Dotsey, who points out that Cornell finds statistically significant interest rate effects of Ml surprises and insignificant base impacts over several recent intervals. 
The above discussion proceeded under the maintained hypothes is that money was the only source of contemporaneous information. Although we have not worked out a solution to the complete model with three signals, we provide some speculations based on results of parallel studies. First, it will be necessary for there to be at least three aggregate shocks if the money stock and interest rate are to be prevented from fully revealing all relevant information. Thus, for example, temporary supply or demand shocks would have to be added to the model.

Second, when there are more signals, it is likely that the extent of agents' reliance on the money supply $(\gamma)$ will be reduced. Intuitively, this is because the additional information reduces the reliance on any one signal (subject to certain restrictions on the covariance matrix of $\mathrm{v}_{t}$ and the signals). Further, agents' expectations will be more precise as more information is added. ${ }^{11}$ However, it is unlikely that these considerations will alter the direction of the channel outlined above, although the magnitude of money supply effects may be reduced.

Thus, we have provided an example of the general idea that money may be nonneutral because it acts as a signal. In contrast to Lucas and Barro, a positive correlation of autonomous money $\left(w_{t}\right)$ and output emerges as a result of contemporaneous monetary information rather than in the absence of such data.

\section{Summary and Conclusions}

Previous studies of the nonneutrality of money (Lucas, Barro) have made the critical assumption that the current money supply cannot be observed. Further, these studies have also assumed that the money supply is determined

11 Notice that this argument overlooks difficulties arising from the fact that the information content of signals is endogenous in setups such as those discussed above. 
exogenously. In this paper, we have shown that relaxing the second assumption has important consequences for the neutrality of money--both perceived (by econometricians) and actual. Once money is permitted to be endogenous, positive comovements in money and output can be obtained even if the current money stock is known to agents.

Above, we analyzed two different situations. In the first case, money reacts to variables which are themselves directly observable. Money is neutral in this case, yet regressions of output on money can produce positive coefficients. In the second case, money acts as a signal for some variable which is itself not directly observable. Here, money is no longer neutral. Changes in the money supply bring about changes in real activity, with a positive comovement being a plausible occurrence. 


\section{References}

Archibald, G. C. and R. A. Lipsey, "Monetary and Value Theory: A Critique of

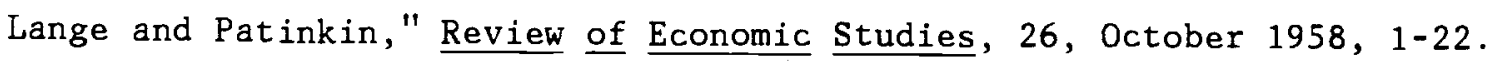

Barro, R. J., "Rational Expectations and the Role of Monetary Policy," Journal of Monetary Economics, 2, January 1976, 1-52.

, "A Capital Market in an Equilibrium Business Cycle Model," Econometrica, 1980 .

and R. G. King, "Time Separable Preferences and Intertemporal Substitution Models of Business Fluctuations," NBER working paper 888 , May 1982.

Boschen, J. F., "Contemporaneous Monetary Information in the Equilibrium Macroeconomic Model: Theoretical Analysis and Empirical Tests," unpublished Brown University dissertation, June 1981.

and H. I. Grossman, "Tests of Equilibrium Macroeconomics Using Contemporaneous Monetary Data," Journal of Monetary Economics, 10, November 1982, 309-334.

Corne11, B., "Money Supply Announcements and Interest Rates: Another View," Journal of Business, 56, January 1983, 1-23.

Enge1, C. and J. Franke1, "Why Money Announcements Move Interest Rates: An Answer From the Foreign Exchange Market," NBER working paper no. 1049, December 1982.

Friedman, M. and A. I. Schwartz, $\underline{A}$ Monetary History of the United $\underline{\text { States }}$, 1867-1960, New York:Princeton University Press, 1963

King, R. G., "Investment and Equilibrium Business Cycle Theory," unpublished, July 1980 . 
, "Monetary Information and Monetary Neutrality," Journal of Monetary Economics, 3, March 1981, 145-206.

, "Interest Rates, Aggregate Information, and Monetary Policy," Journal of Monetary Economics, forthcoming 1983.

and C. I. Plosser, "The Behavior of Money, Credit and Prices in a

Real Business Cycle," NBER working paper 853, November 1981.

Lucas, R. E., "Expectations and the Neutrality of Money," Journal of Economic Theory, 4, April 1972, 103-124.

, "Some International Evidence on Output-Inflation Tradeoffs," American Economic Review, 64, June 1973, 326-334.

, "An Equilibrium Model of the Business Cycle," Journal of Political Economy, 83, December 1975, 1113-1144.

, "Understanding Business Cycles," in Stabilization of the Domestic and International Economy, Carnegie-Rochester Series on Public Policy.

Poole, W. W., "The Making of Monetary Policy: Description and Analysis," Economic Inquiry, June 1975, 253-265.

Trehan, B., "Money, Business Cycles, and the Relative Price of Capital," unpublished working paper, May 1982. 